\title{
CONHECIMENTO DOS PROPRIETÁRIOS DE ANIMAIS DE COMPANHIA SOBRE ZOONOSES NO MUNICÍPIO DE JABOTICABAL- SP
}

\author{
THE KNOWLEDGE ABOUT ZOONOSIS OF DOGS AND CATS OWNERS LIVING IN \\ JABOTICABAL, SÃO PAULO, BRAZIL
}

\author{
B. F. IZOLA ${ }^{1 *}$, J. H. B. TOSCANO ${ }^{1}$, N. C. MARQUES ${ }^{1}$, F. S. MAIROS ${ }^{1}$, L. ALBINO$^{1}$, \\ E. M. N. PAULA ${ }^{2}$, A. P. R. GRISOLIO ${ }^{2}$, A. A. B. CARVALHO ${ }^{3}$
}

\begin{abstract}
RESUMO
O objetivo desse estudo foi avaliar o conhecimento dos proprietários de animais de companhia sobre zoonoses no município de Jaboticabal-SP. Os dados foram obtidos por meio de um questionário, semiestruturado, com 18 questões sobre zoonoses, com foco nas doenças: raiva, toxoplasmose, leishmaniose e leptospirose; durante um período de 7 dias do mês de setembro de 2015. O software utilizado para tabulação de dados foi o formulário do Google Drive. As respostas foram analisadas por estatística descritiva. Participaram da pesquisa 102 pessoas, destas, 57\% afirmaram saber o que é zoonose, mas apenas 40,36\% responderam corretamente quando questionados sobre o que era. Respostas como, por exemplo, "Centro de zoonoses ou doença animal" foram citadas. Quando indagados se o cão poderia transmitir doenças para o ser humano, $24,5 \%$ não sabiam e 5,9\% disseram que não; contra 20,6\% que não sabiam e 4,9\% que não em relação ao gato. Não ouviram falar sobre a raiva, $2 \%$ e $80,39 \%$ acertaram os modos de transmissão e $83,33 \%$ de prevenção da doença. Acreditam que a raiva possa atingir o ser humano $72,5 \%$ dos respondentes, e citaram os cães $(79,4 \%)$, morcegos $(71,6 \%)$ e gatos $(57,8 \%)$ como principais transmissores. Sobre a leptospirose, $89,2 \%$ já ouviram falar, sendo que $63,73 \%$ acertaram os modos de transmissão e apenas $41,18 \%$ de prevenção. Nunca ouviram falar sobre leishmaniose $42,2 \%$, sendo que somente 33,9\% acertaram os modos de transmissão e 88,23\% desconhecem os modos de prevenção. Sobre toxoplasmose, $66,7 \%$ já ouviram falar sobre a doença, sendo que $76,11 \%$ e $87,25 \%$ desconhecem, respectivamente, os modos de transmissão e os modos de prevenção. Observa-se falta de conhecimento em relação à toxoplasmose, leishmaniose, leptospirose e raiva, respectivamente. Programas de educação em saúde que visem atingir proprietários de animais de estimação, principalmente em ambientes como os hospitais veterinários são uma forma de transmitir conhecimento adequado sobre zoonoses.
\end{abstract}

PALAVRAS-CHAVE: LEPTOSPIROSE，LEISHMANIOSE，RAIVA，TOXOPLASMOSE，SAÚDE PÚBLICA.

AGRADECIMENTO: Departamento de Medicina Veterinária Preventiva e a Liga Acadêmica de Saúde Pública Veterinária (LASP).

ÁREA TEMÁTICA: Zoonoses 